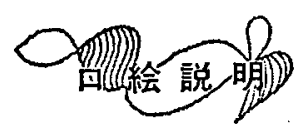

\title{
口絵 1 Secondary Flow Patterns for Centrifugal Instability Phenomena in a Curved Circular Tube
}

(University of Alberta K.C. Cheng and F.P. Yuen)

It is known that.centrifugal instability in the form of the onset of an additional pair of vortices occurs at a certain Dean number near the center of the outer concave wall of a curved square (or rectangular) channel under fully developed laminer flow condition. One may expect the same phenomenon in the curved circular túbe and indeed recent numerical solutions [J. Fluid Mech. vol. 119, p. 475, 1982, Q. J. Mech. Appl. Math. vol. 35, p. 305, 1982] confirm the occurrence.

The centrifugal instability phenomena observed in the curved circular plexiglass tube (inside diameter $=2 a=2.54 \mathrm{~cm}$, radius of curvature $R_{\mathrm{c}}=127 \mathrm{~cm}$ ) at the exit of $180^{\circ}$ bend with sufficiently long straight entrance length are shown in the figure. The smoke is generated by passing air over ammonium hydroxide and injecting hydrochloric acid through hypodermic needle.

The pictures on the right-hand side were obtained by disturbing the flow using a hypodermic needle at $90^{\circ}$ position from the start of the $180^{\circ}$ bend whereas those on the left-hand side represent natural disturbances. The Dean number is defined as $K=\operatorname{Re}\left(a / R_{\mathrm{c}}\right)^{1 / 2}$, where $\operatorname{Re}=\operatorname{Reynolds}$ number, $(2 a) \bar{w} / \nu$, $\bar{w}=$ average velocity and $\nu=$ kinematic viscosity. The experimental apparatus used is similar to that described in Proc. Third International Symposium on Flow Visualization (1983).

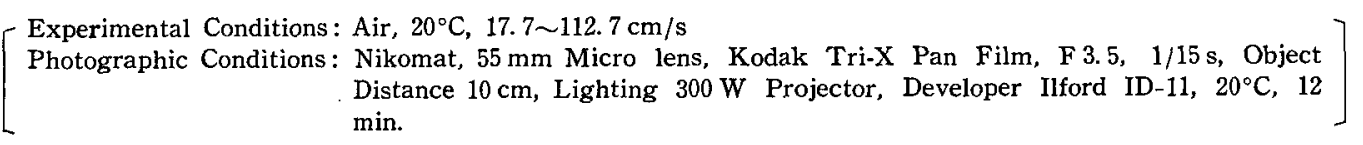

口絵 2 衝繫波 (シュリーレン法)

(航空宇宙技術研究所 西 武德, 藤田敏美)

NACA で開発された NACA 641-212 の模型について, 一様流マッ八数 $M=0.9$ のとさ翼面上に発生した衝撃波 を示す。実験に使用した風胴は，航空宇宙技術研究所 $100 \times 400 \mathrm{~mm}$ 遷音速 2 次元風胴である。シュリーレンの撮 影方法は, 受光部焦点 (ナイフェッシ位置) に7色のカラーフィルタを㨉入するカラーシュリーレン撮影方法であ る。使用したカラーフィルタは, 紫, 赤, 黄, 青, 緑, 橙, 茶色の 7 色が帯状に配列されている。写真のベースを 赤色としたので, 膨張流が黄, 青, 緑, 橙, 茶色の順で密度公配の大きさが表わされる。写真において, 圧縮流は 紫色, 膨張流は黄, 青色で現われている。

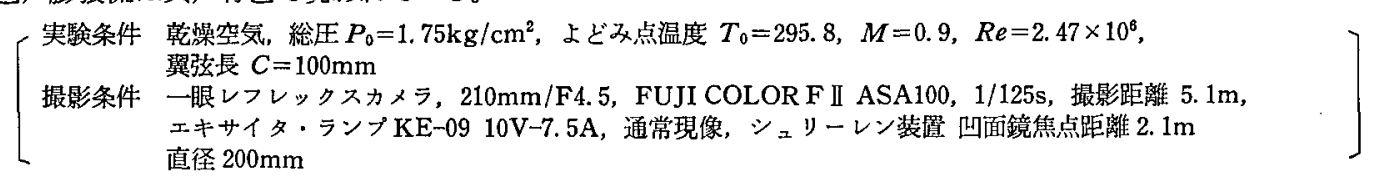

\section{口絵 3 壁乱流の三次元性（水素気泡膜法）}

（徳山工業高等尃門学校 大成博文, 佐賀孝徳, 山本恭子, 山口大学 斎藤 隆)

水素気泡膜法とは，陰極線に直流電圧を印加して水素気泡を連続して膜状に発生させる方法である。壁面に平行 に張られた陰極線から均一に発生した办素気泡は，流下するとともに複雑な 3 次元的挙動を呈する。白く浮きあが る笳状のものが，いわゆる ‘low speed streaks' に相当し，左右の黒く写る高速部に挟むれるように存在してい る。明隌は横からのスリット光によって形成され，それが扰よその高さ表現を可能とする。また，緑色の laser beam’がその 3 次元性の証明に重要な役割りを演ずる。laser beam は上から $y^{+}=10,30$ の高さに㨉入され，それ に気泡が接触すると「鮮点」となる。この 2 本線に的いて，互い鮮点の形成位置が相反する点が注目に值する。 
実験条件 水，大気圧(開水路流れ)，20.0C，平均流速 $7.13 \mathrm{~cm} / \mathrm{s}$ (流れは上から下)；レイノルズ数(水深を代表長さ) 4650 , 水深 $6.57 \mathrm{~cm}$, 陰極線高さ $0.64 \mathrm{~cm}\left(y^{+}=30\right)$

撮影条件 ニコンF2, ニッコール50mm,フジカラー400(ASA400), F1.4.1/60s, 撮影距離約 $40 \mathrm{~cm}$ ，側方から

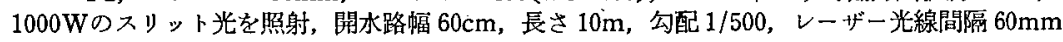

口絵 4 平板上のフィルム冷却（ガスタービンフィルム冷却における吹出孔近傍の物質伝達率分布と吹出流の 可 視 化 (層流型吹出流)）（格子状スカラー量の $2 \cdot 3$ 次元画像表示と煙トレーサ法）

（航空宇宙技術研究所 吉田豊明，三村富剈雄）

高温ガスから構成部材 (タービン翼・然焼器ライナー) を保 護するための有効な方法としてフィルム泠却がある。冷却効果 を高め，かつ主流に及ぼす空力的損失を少なくするためには， 吹出空気が壁面に沿って薄膜状に流れることが必要である。こ こで掲げた結果は平板上の乱流境界層へ層流型の吹出流を供給 した場合の壁面上の情報を示す。

(a)は吹出孔近傍の物質伝達率が，吹出孔のない場合に比べ何 倍になっているかを示す 2 次元表示で，ナフタリン畀華法によ り求めた $33 \times 7$ のデータを画像化したもの。(b)はそれの 3 次元 表示である。スケッチに示寸渦, 衝突流, よどみ域との対応が わかる。

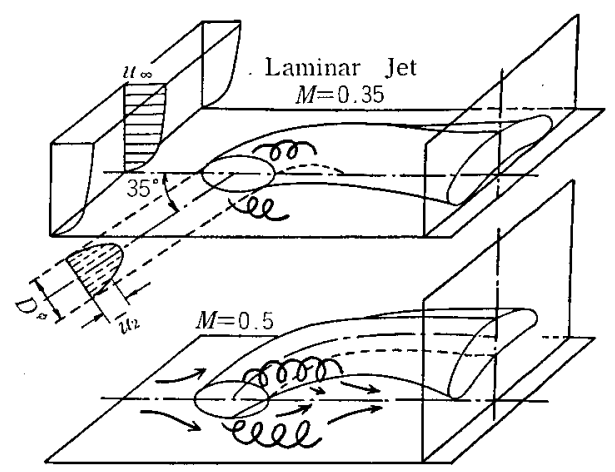

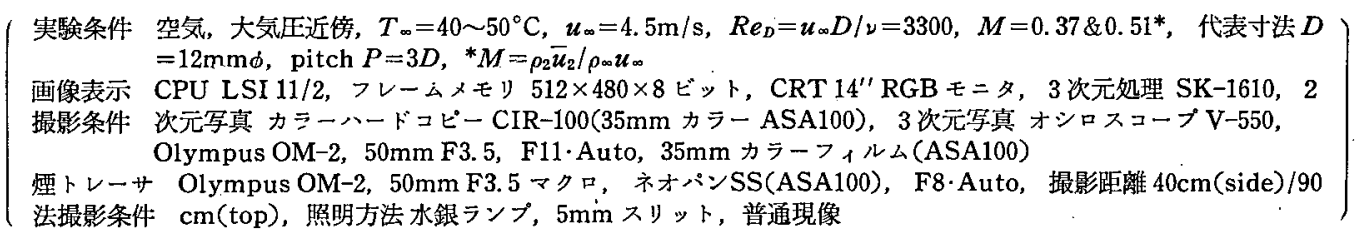

口絵 5 船型試験水槽における水中写真

（石川島播磨重工業 山崎禎昭; 横田孝次） 本文327面参照。

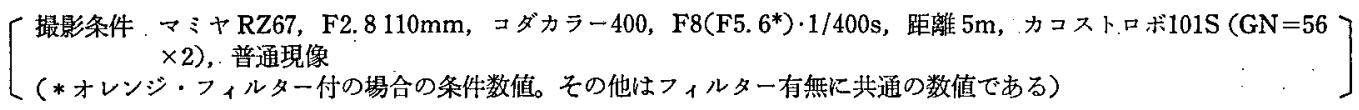

\section{口絵 6 旋回型燃焼器内の流れ（火花追跡法）}

(東海大学 青木克巳, 太田紘昭, 中山泰喜)

旋回型然度器内の非然焼場における流れを空気流により, 正面と側面に配置された 2 台の一眼レフカメラで同時 撮影したものである。正面からは旋回している流れが，側面からは逆流している流れの状態がそれぞれ的確に把 握 することができる。本旋回器は軸流形, 羽根枚数 16 , 羽根角度 $45^{\circ}$ (スワール数 $S=0.78$ ) である。電極は, 側壁に

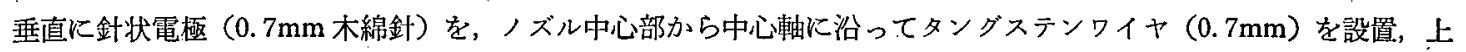
図の測定箇所は $x / D=0.75$ であり，印加電圧 $250 \mathrm{kV} ，$ ペルス数 15 ，パルス周波数 $3.33 \mathrm{kHz}$

[実験条件 空気, 大気圧, $20^{\circ} \mathrm{C}$, 管内平均速度 $2.94 \mathrm{~m} / \mathrm{s}, R e=2.36 \times 10^{4}$, 代表寸法 $D=120 \mathrm{~mm}$

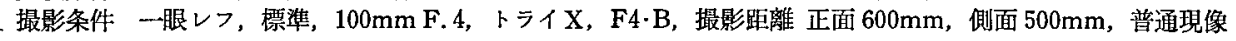

\section{口絵 7 直径方向に 2 次元流路を有するスリット円柱まわりの流れ（半周期の变化）（線香煙法）}

直径方向に 2 次元流路を有する天リット円柱のスリット部が流れと直角に設置された場合, 両スリット部で境界 層の吸込みと吹出しが交互に後流うずの放出周期で規則的に行われる。すなわち，交番的な吸込みと吹出しによる 境界膡制御が行われる ${ }^{1,2)}$ 。このような流れの半周期の時間的変化を円柱前方畦点に線香を埋込んで可視化した例 である。円柱の後流には振動翼と類似のうず列が形成される。 


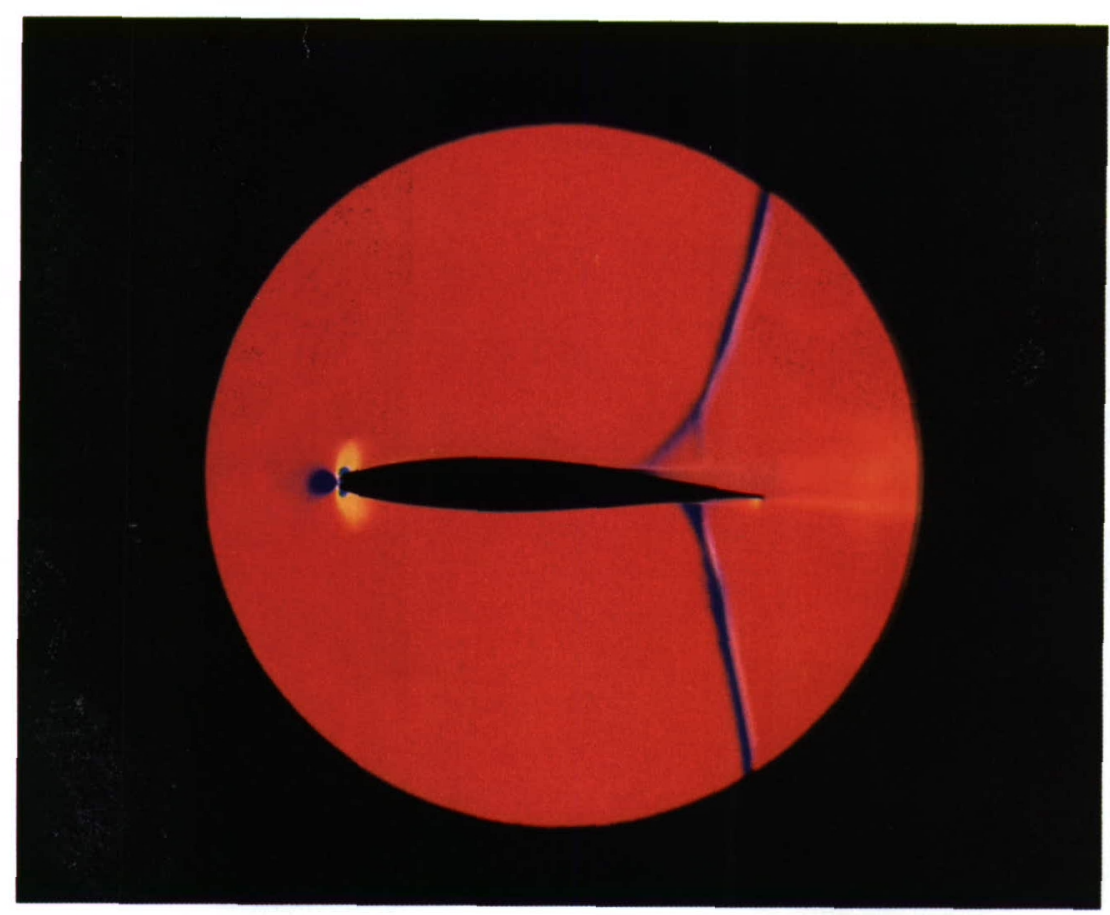

ロ絵 2 衝撃波（シュリーレン法）

(航空宇宙技術研究所 西 武徳, 藤田敏美)

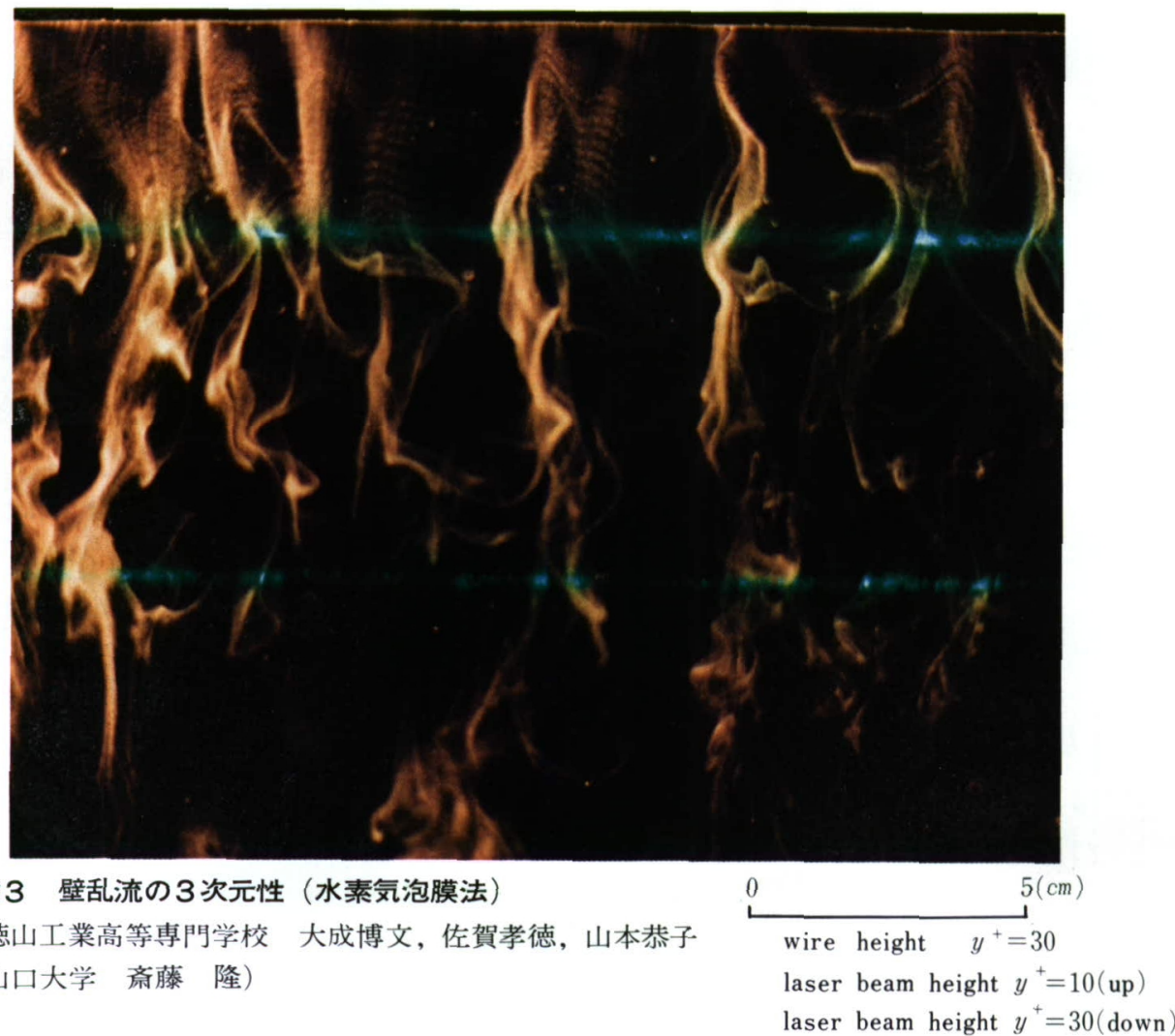

